\title{
Gündelik Hayat: Sosyo-Kültürel Bir Yaklaşım
}

Mevlüt YILMAZ*

Öz: Toplumsal yaşam ve kültürel alan, gündelik hayatın şimdi ve buradalığı çerçevesinde kendini somutlaştırır. Bireysel etkinliklerin ve sosyal etkileşimlerin ortak alanı olarak gündelik hayat, birçok edimsel pratiğin ve toplumsal bağın oluşturulduğu ve geliştirildiği bir birleşme alanıdır. Bu yönüyle sosyal normların, kültürel kodların, tutum ve davranış biçimlerinin görünür kılındığı bir kesişim noktasında bulunur, gündelik hayat. Dolayısıyla gündelik hayatın insani ve toplumsal ilişkilerin odağında yer aldığı söylenebilir. Sosyal yaşamın en sıradan, tekdüze yönleri bile sosyo-kültürel alan ile etkileşim halindedir. Toplumsal ve kültürel alanın çözümlenmesinde gündelik hayat, merkezi bir öneme sahiptir. Çünkü her insan belirli bir gündelik hayata sahiptir ve gündelik hayatın sıradan akışı tüm insanlarca paylaşılır. Belirli yaşam kalıplarının izlerini gündelik hayatta görmek mümkündür.

$\mathrm{Bu}$ çalışmada gündelik hayat, sosyo-kültürel bir bakış açısıyla analiz edilmeye çalışılmaktadır. Kavramsal açıklamaların yanında sosyal teoride yer alan konuya ilişkin makro ve mikro yaklaşımlar ele alınmaktadır. Ayrıca tarihsel gelişim serüveni içerisinde farklılaşan toplumların, iktisadi düşüncelerin, kültürel değerlerin gündelik hayat temelinde sosyolojik bir çözümlemesi amaçlanmaktadır.

Anahtar Kelimeler: Gündeliklik, Gündelik Hayat, Toplum ve Kültür.

\section{Everyday Life: A Socio-Cultural Approach}

Abstract: Social life and cultural field become concrete within the frame of the here and now of everyday life. Everyday life, which is the common area of individual activities and social interactions, is a union area where many actual practices and social ties are formed. In this respect, everyday life is located at an intersection point where social norms, cultural codes, attitudes, and behaviors are visible. Therefore, everyday life can be said to be at the center of human and social relations. Even the most ordinary, monotonous aspects of social life interact with the socio-cultural sphere. Everyday life is critically important in analyzing the social and cultural field because every person has a certain everyday life and the ordinary flow of everyday life is shared by all people. It is possible to see the traces of certain life patterns in everyday life.

The purpose of this study was to analyze everyday life from a sociocultural perspective. Besides the conceptual explanations, macro and micro approaches related to this topic in social theory are discussed. This study also aimed to

* Dr. Öğr. Üyesi, Fırat Üniversitesi İnsani ve Sosyal Bilimler Fakültesi Sosyoloji Bölümü, Elazı ğ/Türkiye. e-mail: mevlutyilmaz@ firat.edu.tr

ORCID: 0000-0002-8982-6778

$\begin{array}{cc}\text { Geliş Tarihi: } 09 \text { Şubat } 2021 & \text { Kabul Tarihi: } 17 \text { May1s } 2021 \\ \text { Received: } 09 \text { February } 2021 & \text { Accepted: } 17 \text { May } 2021\end{array}$

Received: 09 February $2021 \quad$ Accepted: 17 May 2021

Bu makaleye atıf için / To cite this article: Yılmaz, M. (2021). Gündelik Hayat: Sosyo-Kültürel Bir Yaklaşım. Medeniyet Araştırmaları Dergisi, 6(1), 143-162.

Doi: $10.52539 / \mathrm{mad} .877336$ 
make a sociological analysis of differentiating cultures, economic thoughts, and cultural values based on everyday life.

Keywords: Everdayness, Everyday Life, Culture and Society.

\section{Giriş}

Gündelik hayat, birçok disiplinin ortak araştırma nesnesi olmasının yanında sosyo-kültürel alanla da yakın bir ilişki içerisindedir. Bennett (2013:11)'e göre gündelik hayat, toplumsalın oluşturulmasında kültür ve yapı arasındaki etkileşim konusunda devam eden tartışmalar içinde, bu etkileşimin gerçekleştiği alan olması hasebiyle önem arz eder. Bu nedenle son dönemlerde sosyolojik araştırmalarda hem bakış açısı hem de metodolojik bakımdan mikro ölçekte gündelik olana ve gündelik hayatın farklı boyutlarına yoğunlaşan çalışmaların sayısındaki artış, bu ilişkiyi dikkat çekici kılar.

Kişisel ve sosyal yaşamın gerek sıradan, önemsiz ve tekrarlanan gerekse de rutin, düzenli ve istikrarlı yapısı gündelik hayat kapsamında yer alır. Gündelik olan doğaldır ve değişken bir yapıya sahiptir. Bireyin duygusallığı, acıları ve iletişimsel eylemleri bağlamında kişisel tüm etkinliklerini ve bununla birlikte toplumsal olarak da sosyal etkileşimleriyle tüm ilişki dünyasını kuşatır. Gündelik hayat, günlük pratiklerin ve sosyal bağların ortaya çıkarıldığı, geliştirildiği ve yeniden üretildiği bir birleşme noktasıdır. Bu açıdan üretken ve zengin karakteristiğiyle gündelik hayat, bireysel ve sosyal yönden çok boyutlu deneyimlerin geliştirildiği bir ortamı niteler. İnsani ve sosyal etkileşimlerin merkezinde bulunan gündelik hayat, bu ilişkiselliklerin hayati bir temelidir. Ayrıca sosyal yapının aktöre/faile yüklediği anlam bütününün vücut bulma biçimini ve bunun izlerini gündelik hayatta gözlemlemek mümkündür.

Bireysel-toplumsal alanda genelleşmiş yaşam tarzları ve kültürel kodların üretilme gücü, gündelik hayata sosyo-kültürel bir bakış açısını kendiliğinden ortaya çıkarır. Dolayısıyla toplumsal yapı ve kültürel alan bağlamında gündelik hayat, toplumsal ve kültürel yaşamı var eden bireylerin belirli bir uyum süreci içerisinde kavrama, anlamlı kılma ve bunu iletme çerçevesinde oluşturdukları bir gerçeklik olarak değerlendirilir. Bu oluşum gündelik hayatta, toplumsal ve kültürel etkileşimlerin de kökenidir.

$\mathrm{Bu}$ çalışmada gündelik hayatın toplumsal ve kültürel alanla bağlantısı kapsamında kavramsal açıklamalara ve gündelik hayatın kuramsal çerçevesine ilişkin bireysel ve toplumsal bakış açılarına yer verilmektedir. Bu bağlamdan hareketle farklı disiplinlerin, araştırma alanlarının ortak paydasında yer alan gündelik hayatın sosyo-kültürel analizi amaçlanmaktadır.

\section{Gündelik Hayat}

Gündelik hayat toplumu oluşturan bireylerce belirli bir tutarlılık çerçevesinde algılama, anlamlandırma ve anladığını aktarma süreciyle var edilen bir gerçeklik olarak karşımıza çıkar. Bu süreç, gündelik hayatta insani ilişki ve etkileşimlerin temelini oluşturur. Aynı zamanda gündelik hayat, gerçekliğin göz ardı edilen en önemli alanıdır (Polama, 1993: 262). Gündelik hayat tartışmasız bir biçimde dünyamızı çevreleyen sıradan faaliyetlerin vazgeçilmez ve kabul edilmiş sürekliliğini içinde barındırır. Debord (1961: 69) gündelik hayatı, "her şeyin ölçüsü” olarak görür. Gündelik hayatın süreklilik, sıradan olanı ve olağan durumları karşılayan yapısına karşın aynı zamanda 
kavrayışımızdan kaçan ve anlaşılmaya direnen bir niteliği de söz konusudur (Felski, 2000: 77-78).

Gündelik hayat, doğayla dönüștürücü bir praksis içine girilen, yoldaşlığın ve aşkın öğrenildiği, iletişimsel becerilerin kazanılıp geliştirildiği, normatif kavramların pragmatik biçimde uygulandığı çeşitli arzu, acı ve duyguların hissedildiği ve nihayetinde sönümlenen hayati önemdeki bir çevreyi kapsar (Gardiner, 2016: 14).Gündelik hayat, tarihsel olarak kurulmuş pratikler ve diğer yapılar, kurumlar ve pratiklerle karmaşı şekilde bağlantılı ve bunlar vasıtasıyla dolaylanmış öznellik biçimlerinin bir birleşimidir. Heller (1987: 297; Gardiner, 2016: 182)'e göre gündelik hayat, “tek bir şey” değil, daha ziyade özneler arası dünyamızı kurduğumuz ve buna dayanan ortak yaşam deneyimleridir.

Gündelik hayat bir şey ya da sınırları belirli bir faaliyet alanı değildir. Doğa ile kültürün, tarihsel ile yaşantının, bireysel ile toplumsalın, gerçek ile gerçekdışının bir sentezidir, bir geçiş ve buluşma yeridir, iç içe geçme ve çatışma yeri, özetle bir gerçeklik düzeyidir. Bir anlamda gündelik hayat, en basit ve en bariz olanın mekânı; bir anlamda bayağılık, kabalık, tekrarlanan şeydir. Diğer anlamda bundan daha derin bir şey yoktur. Spekülatif olarak aktarılmamış, açığa çıkmış varoluş ve "yaşantı"dır. Değiştirilmesi gereken ve değiştirilmesi en güç olan şeydir (Lefebvre, 2015: 55).

Bütün sıradanllğı ile gündelik hayat tekrarlardan oluşur; işteki ve iş dışındaki tavırların, mekanik hareketlerin yani el ve vücudun devingenlikleri, rotasyon veya gidiş-gelişler gibi durumlar; saatler, günler vs. zamansal ifadeler, çizgisel tekrarlar ve döngüsel tekrarlar, doğal zaman ve akılc1 zaman vb. etkinlikler gibi. Gündelik hayat, nesneleri veya yapıtları üreten etkinliklerin kendilerini yeniden ürettikleri, kendilerini kuran ilişkilere yeniden başladıkları, bu ilişkileri yeniden ele aldıkları ya da tam tersine kademeli değişikliklerin yaşandığı bir analizi mümkün kılması açısından önemlidir (Lefebvre, 2007: 28 29). Bu bakımdan toplumsal yaşamın günlük olarak idame ettirilmesi temelinde biçimlenen gündelik hayat, sosyo-kültürel, ekonomik, politik, sembolik vb. kodları içeren kapsamlı bir olgudur denilebilir.

Gündelik hayat, zengin ve üretken bir yapıya karşılık gelir. Kişisel ve sosyal yönden çok boyutlu deneyimlerin geliştirildiği bir ortamı betimler. İnsani ve sosyal ilişkilerin merkezi alanı olarak mevcut ilişkiselliklerin üzerine bina edildiği temeldir. Dolayısıyla gündelik hayat, toplumsal yapının bireye, bireyin sosyal alana yüklediği anlam bütününün kesişim noktasında yer alır.

\section{Gündelik Hayatın Teorik Hinterlandı}

Gündelik hayatı anlama ve anlamlandırmada psikolojik ve sosyolojik teoride yer alan makro ve mikro yaklaşımlar işlevsel rol üstlenmektedir. $\mathrm{Bu}$ çerçevede gündelik hayatın açılanmasında bireysel ve toplumsal alanın ne derece etkili olduğu netleștirilebilir. Teorik kapsam, toplumsal düzene ilișkin psiko-sosyal makro bakış açıları ve gündelik hayatı doğrudan ilgilendiren rutinlerin ve ritüellerin mikro yaklaşımla ele alınmasını içermektedir.

A. Psikoanalitik Yaklaşım ve Gündelik Hayat

Psikoanalitik teoriler genel anlamda, bireyin davranışını motive eden içgüdüler, arzular ve dürtülerle dolu bilinçsiz bir zihne sahip olduğu fikrine odaklanır. Bu anlayış, Freud (1975)'un insan zihnini üç farklı katmana ya da üç 
farklı bilinç seviyesine indirgemesine ilişkin yaklaşımından kaynak bulur. Buzdağının bir tarafında bilinçli eylemleri yöneten zihin var ve bunun altında da bilinç öncesi zihin yer alır. Diğer ve en büyük kısmı ise bilinçsiz eylemlerin merkezindeki zihin oluşturur. Freud'a göre gündelik hayatta deneyimlediğimiz davranışlar, zihnin bu büyük bölümünde yer alan derin duygusal dürtüleri ve çatışmaları yansıtır (Scott, 2009: 11).

Freud, gündelik yaşamın psikopatolojisini toplumsal alana etkileri bağlamında araştırır. Ona göre gündelik yaşamın idamesi sırasında karşılaşılan dil sürçmeleri, sözcüklerin unutulması, çocukluk anılarının etkileri, yanılmalar, sorunlu edimler aslında zihnin duygusal çatışmalar yaşadığı alanla ilgilidir (Freud, 1996).

Psikanaliz yaklaşımın temelini kişilik içinde birbiriyle rekabet içinde bulunan üç güç; id, ego ve süper ego oluşturur. İd acil tatmin edilmesi gereken dürtülerin kaynağı iken süper ego, ebeveyne ait otorite ile toplumsal otoritenin içselleştirilmesidir. Ego ise ortaya çıan ya da çatışan taleplerde orta yolu bulmaya çalışır (Marshall, 2009:605). Süper ego bu anlamda bireyin kültürel değerlere göre nasıl davranması gerektiği konusunda denetim mekanizması işlevi görür.

Gündelik hayat, insanların zevk ilkesi ile gerçeklik ilkesi arasındaki rekabetten bir uzlaşma çıkarmaya çalışması yanında aslında bu üç gücün sürekli bir savaş alanına da karşı1lı gelir. Örneğin "medeniyet" kavramı bu ilişkisellikten doğar ve insanoğlunun bilinçdışı olgunlaşmamış, vahşi duygularının toplumsal dünyadaki deneyimler çerçevesinde "evcilleştirildiği" bir süreç olarak görülebilir. Bu anlamda N. Elias (1994) da Freudcu yaklaşımı uygarlaştırma süreciyle geliştirmeye çalışır. Elias, ilkel içgüdülerimizde nasıl ve niçin uygarlaşma ihtiyacı doğduğunu ve toplumsal görgü kurallarının hangi sosyal amaçlara hizmet ettiğini sorgular (Scott, 2009: 11).

Birey gündelik hayatını idame ettirirken bazı duygu ve düşüncelerini açıça ifade ederken toplumca kabul edilemez olanlarını bastırma eğilimi taşır ve bunları gizler. Bastırma, Freud'un bilinçdışı dürtüleri idare etme ve uygarlaşma yolunda hayatta kalabilme amaçlı oluşturulmuş savunma mekanizmalarından biridir. Bunun gibi bireyin sağlıklı bir maddi ve manevi yaşam sürdürebilmesinde çeşitli (mantığa vurma, neden bulma, yansıtma vb.) mekanizmalar işlevsel görülür. Ancak bu tür mekanizmalar bireyin geleneksel ve kültürel bağlar kurmasına engel teşkil ettiği andan itibaren sağlıssı olarak nitelendirilir. $\mathrm{Bu}$ anlamda bazı bireyler savunma mekanizmalarıyla olumlu etkinliklerde bulunur, bazıları ise anormal davranış sergilemeye eğilimli olabilir.

Bireyin bilinçdışı zihin çerçevesinde davranışlar sergilemesi ya da savunma mekanizmalarıyla hareket etmesi diğer bireylerle ilişkilerine ve sosyal etkileşimin yapısına da yansır. Dolayısıyla toplumsal alanda bireylerin kuracakları etkileşimlerde bilinçli/bilinçdışı zihin yapısının ve niteliğinin gündelik hayatta yansıma alanı bulduğu ve gündelik olana dönük değerlendirmelerde bireyin psikolojik yaşantısının önem arz ettiği söylenebilir.

B. Sosyal Psikoloji ve Gündelik Hayat

Psikoanalitik yaklaşımın gündelik hayatta bireyin bilinçdışı güçlerinin onun gündelik yaşantısındaki duygu, düşünce ve davranışlar üzerindeki etkileri dolayımında şekillendiğine ilişkin bakış açısı, sosyal psikolojik yaklaşım 
tarafindan eleştirilir. Sosyal psikolojik perspektifte gündelik hayat, birey ve çevresi arasındaki karşıllıklı etkileşim bağlamında ele alınır. Psikoanalitik yaklaşımda bilinçdışı güçlerin gündelik hayatını idame ettiren birey üzerindeki etkilerine yoğunlaşıllırken sosyal psikolojik anlayış da ise gündelik etkileşimlerin toplumsal adaptasyon, peşin hükümler çerçevesinde daha geniş bir hinterlantta değerlendirilmesi gerektiği üzerinde durulur.

Sosyal psikoloji bireyin diğer bireylerle ve genel toplumsal çevresiyle girdiği ilişkileri incelemeye ve anlamaya çalışan geniş bir alana karşılık gelir. İnsanoğlunun bireysel bir varlık olması yanında çevresiyle de etkileşim halinde bulunması onun toplumsal bir varlık olduğunun göstergesidir. Bireyin sosyal yönü ve sosyal olanın birey üzerindeki etkileri sosyal psikolojik anlayışın temel araştırma nesnesidir. Bireyin hem kendisine hem de sosyal çevresine uyum süreci, itaat ve ön yarg1 gibi çeşitli sosyal psikolojik konular (Sayar ve Dinç, 2013: 141-151) bireyin gündelik hayat pratikleri üzerinde de doğrudan ya da dolaylı bir etkiye sahiptir.

Sosyal psikolojik yaklaşımda birey zihninin biçimlendirilmesinde sosyal bağlamın üstlendiği rol incelenir. Bu anlayışta toplumsal dünya, birey üzerinde dönüştürücü güce sahip bir dış çevrenin varlığıyla nitelenir. Diğer insanlar, etkin bir biçimde tepki verilen uyaranlardır ve bireyin yanıtları da o insanların dünyaları için birer uyarandır. Bu bakımdan bireyin gündelik hayat deneyimlerini de edindiği bilgiler bağlamında işlediği bir alan, bu uyaranlarla karşılaşma ve bunlarla baş etme stratejileri olarak değerlendirilebilir. Sosyal psikoloji gündelik hayatta uyaranların nasıl yorumlandığ getirildiği ile ilgilidir ve bu yönüyle bilişsel psikolojiyle de iç içedir (Scott, 2009: 12).

Arygle (1972: 16)'a göre kişilerarası davranış, insanlık için evrensel nitelikteki bir dizi sosyal motivasyon tarafindan yönlendirilir. Bunlar bir tarafta yeme, içme, dinlenme gibi toplumsal etkileşim üretebilen sosyal olmayan dürtüler; özellikle güç ve iktidar konumundaki insanların rehberliğine, onayına, yardımına, etkileşimine ve yardımına bağgllık güdüsü; akran grupları ve akranlar tarafindan kabul edilme ve fiziksel yakınlık, göz teması sıcak ve samimi tepkiler gibi yakın ilişkiler; grup üyeleri ve diğer gruplar tarafından görev lideri olarak çoğu zaman konuşma, karar alma ve grup tarafindan yönlendirilmeye izin verme bağlamında üstünlük iliş̧isi; genellikle karşı cinsten çekici akranlarla, fiziksel yakınlık, bedensel kontakt vb. göz teması, sicak dostluk ve samimi sosyal etkileşimin kaynaklık ettiği cinsiyet ilişkileri; fiziksel, sözel ya da başka biçimlerde ötekine zarar verme şeklinde saldırganlık; birey açısından ötekilerin onaylayıcı yanıtlar vermesi ve öz imajı geçerli olarak kabul etmesi için özgüven ve ego kimliği; ve son olarak da Arygle (1994: 24) değer, ilgi, para ve başarı istenci gibi sosyal davranışı etkileyen diğer motivasyon yapılarını ele alır.

Sosyal davranış üzerinde etkili olan bu tür motivasyonel faktörler bireyin toplumsal yaşamını idame ettirirken gündelik hayat pratikleri üzerinde de yansıma alanı bulur ve bireyin normal davranışlar sergilemesi, toplumsal çevreye uyum göstermesi ya da agresif etkinliklerde bulunması gibi durumlarda yönlendirici rol üstlenir.

Sosyal psikologlar insanoğlunun oluşturmuş olduğu, diğer insanlarla az ya da çok etkili biçimde başa çıkmaya yardımcı olabilecek toplumsal beceriler repertuarı üzerinde dururlar. Aynı zamanda bununla bağlantılı, başkalarına 
ilişkin algılarımızda yapılan hatalarla da ilgilenirler. Onlara göre bu hatalar bilginin işlenmesindeki bilişsel hatalardır, ancak toplumsal yaşam deneyimleri için temel önemdedir. Sosyologlar ise insan benliğinin biçimlendirilebilir bir yapısının olduğunu ve her durumun normatif taleplerine göre biçim değiştirebileceğini ileri sürerler. Örneğin davranışsal farklılıklar, bireysel biliş yapısı ve süreçleriyle bağlantılı olduğu kadar kültürel normlar ve beklentilerle de ilişkilidir (Scott, 2009: 13-14). Bu durum gündelik hayat deneyimlerinin psikolojik etkileşimlerin vurgulanması anlamında önem arz eder. Salt zihinsel süreçlerin yanında toplumsal normların, değerlerin, kültürel kodların etkisinden söz edilebilecek bir gündelik hayat idamesinden söz etmemiz gerekir. Sosyal psikolojik yaklaşım benlik ile sosyal yaşamın etkileşim alanlarından hareketle gündelik olana ilişkin analizlere imkân sağlaması bakımından değerli görülür.

\section{Yapısal Fonksiyonalizm ve Gündelik Hayat}

Sosyolojik literatürde, toplumsal düzene ilişkin en kapsayıcı ve makro teorik yaklaşım yapısal fonksiyonalizm olarak bilinir. Fonksiyonalizm, sosyokültürel olguların yine toplumsal-kültürel sistem içinde yerine getirdikleri işlevlerin çözümlenmesine odaklanır. Bu yaklaşımda toplum, hiçbir kısmı bütünden ayrı anlaşılamayacak ve birbirleri ile bağlantılı parçalardan oluşan bir sistemdir (Wallace ve Wolf, 2012: 43), yani toplum canli bir organizma gibidir ve organizmayı oluşturan parçaların tümü onun için fonksiyonel niteliktedir. Herhangi bir parçada meydana gelebilecek değişim diğerleri üzerinde de etki potansiyeline sahiptir.

Durkheim (1982), bireysel davranışın dış bir varlık olarak toplumsal yapıdan türeyen sosyal güçler tarafından yönlendirildiğini ileri sürerek işlevselci yaklaşıma önemli katk1 sağlar. Ona göre, gündelik hayatta gözlemlenen örüntüler ve ilişki yapıları, bu temel güçleri ve hizmet ettikleri toplumsal işlevleri ortaya çıkardıkları sürece ilgi çekicidir. Örneğin dini ibadet etkinlikleri, inananları arasında ortak değerlere bağl1lık vasıtasıyla sosyal dayanışma duygusu yaratarak kolektif bir yap1 inşa eder. Buradaki vurgu toplumsal davranışta fikir birliği, uyum ve düzen üzerinedir. Bu durum toplum tarafindan çoğu zaman sosyal düzenin neden ve nasıl korunduğunu da açıklar (Scott, 2009: 15). O, toplumsal sistemin amacının uzlaşma(consensus) yoluyla düzenin kurulması olduğunu vurgular. Durkheim'a göre, uzlaştırıcı kurallar ve değerler sistemi kolektif temsiller veya başka bir ifadeyle kendinde var olan ve bireysel faillerden bağımsız kolektif bilgiler bütünü vasıtasıyla sürdürülür (Bennett, 2013: 12).

Parsons işlevselciliğe yapıyı eklemleyerek, toplumun kendi üyelerinin üstünde ve ötesinde, kendine has bir yaşam ve yapıya sahip, canlı bir varlık olduğu düşüncesini bilimsel bir çerçeveye yerleştirir. $\mathrm{O}$, tüm toplumları farklılaşan alt sistemlerden oluşan, tümü karşılıklı ilişki ve bağımlılık içinde özgürce ve kendine yeten sistemler biçiminde değerlendirir. Bu alt sistemler her toplumun varlığını sürdürülebilir kılmak için dört temel ihtiyacın karşılanmasına imkân sunar. Bunlar uyum, amaca ulaşma, bütünleşme ve varlığını sürdürmedir (Slattery, 2008: 376-377).

Aslında Parsons (1951) Durkheim'den etkilenerek sosyal sistemlerin fonksiyonelliğine yoğunlaşır. Bireyin gönüllü sosyal eylemlerle sistemler oluşturduğunu iddia ederek fonksiyonalizmin yapısal gelişimine katkı sunar. Her ne kadar kültürel değerler ve normlar, bireysel eylemlere ket vursa da 
bireylerin toplumsal yapılara, sosyal kurumlara karş1 nasıl tepkide bulunabileceklerine ilişkin tercih yapabilme firsatları vardır (Scott, 2009: 15).

Durkheim'den Parsons'a kadar yapısal işlevselci ana akım gelenek, toplumsal yapının başatlığı bağlamında faili/bireyi, davranışları, gündelik etkileşimleri vb. tüm etkinlikleri bakımından pasif bir konuma indirgeyerek yapının belirleyiciliği üzerinde durur. Bu durum gündelik hayatı idame ettiren temel aktör olarak bireye karşı mesafeli bir bakışı beraberinde getirir. Yapısal işlevselcilikte bireye karşı toplum, faile karşı yapı ve mikro olana karşı makro perspektifler gibi dikotomilerin varlığı bu mesafenin temel kaynağıdır (Esgin ve Özben, 2018: 35-37). Daha açık ifade edilecek olursa bu yaklaşımın perspektifinden gündelik hayatta toplumsal aktörler kültürel eblehler olarak değerlendirilir. $\mathrm{Bu}$ aktörler uzlaşımsal veya sınıfsal menfaatlerin yansıması niteliğindeki sosyal roller ve eylemsel normları pasif bir biçimde içselleştirerek, genelde refleksif bir tarzda sosyal yapıyı ve kurumları yeniden üretirler (Gardiner, 2016: 17).

Yapısal fonksiyonalist yaklaşım, gündelik hayat pratikleri açısından birey ve bireyin çevresiyle olan etkileşiminde, onu edilgen bir konuma indirger. $\mathrm{Bu}$ yaklaşıma göre, toplumda kültürel kodların ve yapısal süreçlerin belirleyiciliği söz konusudur. Birey sosyal yaşamın temel normlarına uyum göstermek zorunluluğu içerisindeki pasif kültürel kuklalar olarak görülür. Bauman (2011: 16-17)'a göre, modern toplumsal kurumlar bireylerin doğru olanı yapmaları için sürekli bir dış gücün belirleyeceği standartlar çerçevesinde hareket etme zorunluluğundadır. Çünkü bireye bu konuda güvenilemeyeceği savunulur.

D. Yorumsamacı Sosyoloji ve Gündelik Hayat

Gündelik hayat teorisyenlerinin büyük bölümü, yorumsamacı sosyoloji geleneği içerisinde kabul edilir. Bu yaklaşım daha çok Weber'in sosyal eylemin yorumlayıcı kavrayışı olarak değerlendirdiği sosyoloji tanımına dayanır. Weber, modern batı toplumlarını son derece yüksek rasyonellik seviyeleri ile karakterize eder. Batı kültürlerinin baskın değeri olarak rasyonelleşme, toplumsal kontrol açısından da işlevseldir. Ayrıca Weber, bürokrasi kuramı ile gündelik hayata sirayet eden ve onun kanallarını kolonileştiren yapıya işaret eder. Yine profesyonelleşme olarak kalıplaşan modern çalışma kültürü de Weber'in gündelik hayat bağlamında ele aldığı bir diğer konudur (İnglis, 2005: 7-9).

Weber bireyler tarafından toplumsal normların içselleştirilmesinin yalnızca pasif bir boyun eğmeyle sonuçlanmadığını, bunun yanı sıra kendi kendini güdülendiren eylem potansiyeline de kaynaklık ettiğini savunur. $\mathrm{Bu}$ nedenle Weber, örneğin sosyal statü olgusunu analiz ederken, sosyal statünün bir taraftan kapitalist sosyal ilişkilerde yapılaşarak kökleştiğini diğer taraftan da sosyal ilişki seviyesinde fiili karş1lık olarak, bireylerin statülerini belirtmenin yollarını bulmada yaratıcılıklarına (Bennett, 2018: 13-14) vurgu yaparak, bireyin gündelik hayata ilişkin toplumsal eylem potansiyeli merkezli bir açılama geliştirir.

Yorumsamacı sosyolojide sembolik etkileşimcilik, dramaturji, etnometodoloji, fenomenoloji, gibi teorik yaklaşımların gündelik hayata dair açıklamaları dikkat çekicidir. Sembolik etkileşimci yaklaşım, toplumun mikro boyutlarına, gündelik deneyimlerine, içinde yaşanılan gündelik dünyanın ve 
insanların sembolik iletişim vasıtasıyla gündelik hayatlarında nasıl ilişki kurup etkileştiklerine, düzen ve anlamı nasıl inşa ettiklerine yoğunlaşır. Belirli durum ya da yaşam tarzlarıyla ilişkili bireyleri motive eden dinamikleri tespit etmeye çalışır (Slattery, 2008: 333-334). G.H. Mead, Zihin, Benlik ve Toplum adlı çalışmasıyla bu yaklaşıma öncülük eder. Ona göre insanoğlu, aktif bir zihin ve benlik yapısına sahip yaratıcı bireydir (Layder, 2006: 79-80) ve zihin de benlik de gündelik hayatın toplumsal eseridir. İnsan toplumu, zihinsiz ve benliksiz var olamaz, çünkü onun en temel niteliği, toplum üyelerinin zihinleri ve benliklerinin varlığıdır (Swingewood, 1998: 311). İnsan özellikle sosyal bir varlıktır ve toplum da bireyin kendi çevresinde oluşturduğu devamlı bir akışkanlık, devamlı bir oluşum hali ve yeniden yaratma, yorumlama, müzakere ve kavrama sürecini içeren bir dünyaya karşılık gelir. Biz hem birey hem de toplumsal varlı̆̆ız. Hem toplumu etkileyerek dönüştürürüz hem de toplumdan etkilenerek dönüşürüz (Slattery, 2008: 336).

Blumer ise, etkileşim olayını basit bir uyarıcı-tepki ilişkisi olarak değerlendirmez. $\mathrm{Bu}$ ilişkiyi uyarıc1-yorumlama-tepki ilişkisi olarak geliştirir. Benlik sunumu sırasında bireylerin kendileri için birtakım uyarıcılara işaret ettiklerini, sonra bu uyarıcıların görünümünü kendilerince yorumladıklarını savunur. Sembolik etkileşimci yaklaşımda insan eylemindeki anlamın önemi ve kaynağı, yorumlamada anlamın konumunu gösteren üç temel önerme vardır: Bireyler şeylere, şeylerin onlar için ne anlama geldiğine göre davranırlar. Şeylerin anlamı bireyin diğer bireylerle sosyal etkileşimi sonucu oluşur. Son olarak şeylerin anlamı, bunlarla yüzleșen bireyler vasıtasıyla geliştirilir ve yorumlama süzgecinden geçerek değiş̧irilir (Wallace ve Wolf, 2012: 289-295). Blumer, sosyal etkileşimci bakış açısıyla öznel anlamlar ve bireysel dayanaklar vasıtasıyla kendi yaşantı dünyalarını şekillendiren aktöre/faile vurgu yapar. Toplumsal etkileşimde inşa edilmiş olan ortak paylaşımsal anlamlar ve farklı anlam dünyaları önemlidir (Esgin, 2018: 21).

$\mathrm{Bu}$ isimler yaklaşımlarında birey ve toplumu ayrılmaz ve birbirine bağımlı birimler olarak kavrarlar. Benlik ve karakterin sosyal gelişimine ve sembolik eylemlerin anlamları üzerine alakadar olmaları bu geleneğin biçimlenmesinde önemli bir rol üstlenir (Binay ve Tatlıcan, 2018: 166).

Dramaturjik yaklaşımın temelleri, E. Goffman'in (1959, 2009) Gündelik Hayatta Benliğin Sunumu adlı çalışmasına dayandırılır. Goffman, bireye ilişkin hem roller bağlamında benliğin doğası hem de mikro-sosyal normlarla ilişkili kurallar üzerinde durur.

Goffman'a göre, gündelik hayatta birey, aktör gibi gönüllü ya da gönülsüz eylemlerde bulunarak benliğini ifade etmeye çalışır. Bu sırada diğer bireylerin kendisi hakkında izlenimlerde bulunacağını bilir. İzlenim yönetimi bağlamında birey toplumca meşru görülen ideal izlenime uygun etkinlikte bulunur (Güven, 2018: 114).Goffman bireyin, etkinliklerini başkalarıyla ortak düzene koyarak rol alma yerine, başkalarının kendilerine ilişkin izlenimlerini denetleme adına bilerek ve çarpıtarak rolünü yerine getirdiğini belirtir. $\mathrm{Bu}$ durum, gündelik yaşamın etkileşim kaynaklı ritüelleriyle oluşur (Adler, 1987: 220; 2012: 118). Goffman'a göre, sosyal rollerin içselleştirilmesi olarak gündelik hayat, pratik deneyim vasıtasıyla bireylerin sahne önü ve arkası benlikler yaratarak rollerini idare ve onlar arasında müzakere etmeyi öğrendiği bir alandır (Bennett, 2013: 14). 
Goffman'ın dramaturjik yaklaşımında bütünü oluşturan parçalar mikrososyolojinin bilimsel nesneleri bağlamında bütünlüklü bir biçimde ele alınır. Bireyin düşüncelerine önem veren ne kadar çok insan varsa o kadar çok farklılaşan toplumsal benliğin varlığından söz edilir. Böylece gündelik hayatta birey, hesap makinesi keskinliğiyle etkinlikte bulunan bir otomat değil, daha çok etrafından gelecek farklı tepkileri zihninde tutan bir varlık olarak değerlendirmek gerekir (Orhan, 2018: 209-210).

Etnometodolojik yaklaşımda ise, H. Garfinkel'in Etnometodoloji Incelemeleri (1967) adlı çalışması temel önemdedir. Bu yaklaşım bir dizi ilkeye dayandırılır. Bunlar săgduyusal bilgi ve ilişkili faillik durumudur. Sağduyusal bilgi aslında sıradan bireyin gündelik kavrayışlarını içerir. Faillik ise refleksivite (bireyin kendi eylemelerine bir an bile kesintiye uğratmadan pratik olarak dikkat kesilmesi) bağlama-gönderimlilik (faaliyetlerin bağlamı kapsamında ele alınması) açıklanabilirlik (betimleyici açıklamalar) dolayımında bireyin gündelik hayattaki aktifliğine atıftır (Binici ve Tatlıcan, 2018: 216223).Garfinkel'in yaklaşımında, gündelik hayat dünyası nasıl mümkün olur? sorusu merkezidir. Gündelik hayatın rutinleşmiş, standart hale gelmiş yapısına dikkat çeken arka-plan özellikler ve gündelik hayatta etkileşimlerde kullanılan temel metotlar sorunun cevabına ilişkin kavramların genel çerçevesini çizer. Ona göre, insanlar gündelik hayatın arka plan niteliklerini eylemlerin zemini kılarak faaliyetlerde bulunurken çeşitli günlük metotları kullanır ve bu bağlamda gündelik hayat dünyası mümkün olur (Binici ve Tatlıcan, 2018:233). $\mathrm{Bu}$ bağlamda etnometodolojik yaklaşım, insanların gündelik yaşamdaki etkinliklerini hem kendine hem de başkalarına açıklama adına başvurulan yöntemlerin analizi olarak değerlendirilebilir. Etnometodologlara göre, gündelik hayat dünyası insanların birlikte oluşturduğu ve sürekli olarak yeniden üretilen bir alandir (Marshall, 2009: 217).

Garfinkel, yapısal fonksiyonalist bakış açısına muhalefet ile gündelik hayat fikrini geliștirir. Örneğin Durkheim'in toplumsal olgunun kendisini nesnel gerçeklik olarak dayattığ d düşüncesine ciddi eleştiriler yöneltir. Ona göre toplumsal olgular nesnel yapıdan ziyade sıradan bireyin gündelik hayattaki etkinlikleriyle biçimlenen bir niteliğe sahiptir. Yani gündelik hayat dünyası aşkın bir gerçeklik değil daha çok gündelik/spontane ortaya çıkan bir gerçekliktir (Binici ve Tatlıcan, 2018: 216).

Son olarak fenomenolojik yaklaşım ise, "birey ve onun bilinçli deneyimleriyle başlayan önceden var olan kabuller, ön yargılar ve dogmalardan kaçınmayı" içerir (Wallace ve Wolf, 2012: 349). A. Schutz'un Toplumsal Dünyanın Fenomenolojisi adlı çalışması, özgün bir fenomenolojik yaklaşım geliştirmeye yöneliktir. Schutz, gündelik sosyal yaşamın onu deneyimleyenlerin bilinçleri kapsamında ele alınması gerektiğini belirtir. Çünkü her birey toplumsal dünyaya ilişkin belirli bir niteliğe ve içeriğe sahip bilgi ağından hareketle gündelik hayatını oluşturur ve yaşamını idame ettirirken bu networkun odağında kendisini bulur. Yani bir vakitte dünyanın bireye nasıl göründüğü ve algılandığı o andaki bu ağın neresinde yer aldığıyla ilişkilidir. Ayrıca gündelik hayatta etkileşimde bulunduğumuz dünya hakkındaki bilgilerimiz eksiktir. Yani herhangi bir konuda kişinin sahip olduğu bilgi kısmidir ve eksik bir kavrayışı barındırır. Bu açıdan Schutz için bireyin gündelik hayat durumlarına atfettiği anlam, önem arz eder (Şentürk, 2018: 252).P. Berger ve T. Luckmann ise, Gerçekliğin Sosyal İnşası adlı çalışmalarında gündelik hayatı, insanlar 
vasıtasılya yorumlanan ve tutarlı bir dünya olması bakımından sübjektif ve anlamlı gelen bir gerçeklik olarak değerlendirir. Gündelik hayat, bedenin buradallğ $l$ ve mevcudiyetin şimdiliği etrafında organize edilir ve gerçeklik olarak olduğu gibi kabul edilir. Gündelik hayat dünyası hem mekânsal hem de zamansal olarak yapılanır. Bireyin dünyadaki varlığı gündelik hayat tarafindan kesintisiz düzenlenir ve onunla kuşatılır. Gündelik hayatın toplumsal gerçekliği, yüz-yüze etkileşimlerin burada ve şimdiliğinden uzaklaştıkça giderek anonimleşen tipleştirmelerin devamlı bir ardışıklığı içinde kavranır (Berger ve Luckmann, 2008: 31-50).

Yorumsamacı sosyolojinin bu temel yaklaşımları, failliği ve eylemi vurgulayarak gündelik hayatın bağlamsal etkinliklerine odaklanır. Gündelik hayatı ontolojik perspektiften hareketle yapısal olana, makro nesnelere gündelik dünya içinde kurulan şeyler olarak kavrarlar (Binici ve Tatlıcan, 2018:215).

\section{E. Eleştirel Yaklaşımlar ve Gündelik Hayat}

Son dönemlerde gündelik hayata ilişkin daha çok eleştirel bir bakış açısı gelişim gösterir. $\mathrm{Bu}$ perspektifler içinde Lefebvre, gündelik olanın diyalektik vizyonundan hareketle özgürleştirici imkânlar ile yabancılaştırıcı güçler arasındaki çatışmayı gündelik olarak değerlendirir. $\mathrm{Bu}$ temelde gündeliklik, kurumsallaşmış yetkinliğe ve teknik uzmanlığa karşı verilen bir mücadele alanıdır. Lefebvre'e göre, gündelik hayat uzmanlaşmış bütün yetkinliklerin kaldırılıp atıldığında geriye kalan şeydir (Köse, 2018: 306-308). Lefebvre (2007: 47), gündelik hayatın iki kanadı olduğunu belirtir. İlki gündelik hayatın sefaletidir; usandırıcı vazifeler, hor görülmeler, işçi yaşam tarzları, gündelikliğin yükünü taşıyan kadınların yaşamı. Para, metalarla kurulan vahşi ilişkiler. Rakamların egemenliği, yinelenme, kıtlığın devamlılı̆̆ı ve yoksulluğun uzantıları, biriktirmenin, yoksunluğun isteklerin bastırılmasının ve aşağılık bir cimrilik alanı olarak ifade edilir. İkincisi ise gündelik hayatın büyüklügüdür; gündelik hayat üzerine inşa edilen yaşamın sürekliliği. Bedenin zaman ve mekânın, istemenin adaptasyonu çerçevesinde değeri bilinmeyen pratikler: Adresler ve haneler gibi...

Modern çağla beraber gündelik hayat, gelişen bilinç ve kültür endüstrilerinin kuşatıc1 niteliğiyle üretici/özgürleştirici düşünce ve eylem şekillerinin sahnesi olmaktan çıkar. Bu niteliği ile gündelik hayat, artık tarihsel politik devrimlerin gerçekleştirildiği yer değildir, çeşitli üslupların ve kimliklerin temel mücadele alanıdır. Aslında modern toplum, tüketimi gündelikleştirerek ve onu tüketerek bir yanılsama yaratır. Bu yaşam biçimi büyüme ve gelişmeye dayanan ve hayatı hız üzerinden organize eden bir geçicilikle gündelik hayatın devrimci yönünü sekteye uğratarak dünyayı bütünlüklü anlamakta sorun yaşayan yabancılaşmış ve parçalı bir bilince sahip bireyler üretir. Bu durum tarihsellik ile gündeliklik arasındaki gerilimlerin bir sonucudur (Köse, 2018: 338-339).

$\mathrm{Bu}$ anlamda gündelik hayatın eleştirisi, var olan değerleri ideolojik oldukları söylendiği için yok etmek yerine, bunların gündelik yaşam kapsamındaki dönüşümlerini ve gündelik yaşamın gerek gerçek gerekse değer olarak ortaya çıkışını analiz etmeyi kapsar (Lefebvre, 2017: 21).

Gündelik hayata bir diğer eleştirel bakış M. de Certeau $(1988,2002)$ tarafından geliştirilir. Gündelik Hayatın Keşfi adlı çalışmasında, insanların sıradan yaşamlarında herhangi bir şeyi nasıl ele aldıkları konusundaki gündelik 
pratiklerin temelini oluşturan ortak mantığı çözümlemeye çalışır (Sheringam, 2006: 213). De Certeau yaklaşımında, tüketime karş1 üretim, okumaya karş1 yazma, taktiklere karşı stratejiler, sözlüye karşı yazılı gibi ikili terimleri kullanır (Highmore, 2002: 154). O, elle tutulur gündelik pratiklerin analizini yaparak özgün bir gündelik hayat kuramı ve eleştirisi geliştirir. Sosyo-kültürel alanı anlamanın yolu, onu var eden gündelik hayat pratiklerinin anlaşılmasıyla mümkündür. Ona göre, gündelik tüketim etkinliklerinin önemli bir bölümü taktiksel nitelikte olup, kurnazlığı, manevraları, simülasyonları, yanıltmaları içerir. Taktikler ve stratejiler ise birbirine zıttır. Stratejiler belirli bir uzamı sömürgeleştirmeyi hedefler; test edilmiş panoptik pratiklerin bileşimiyle mekâna egemen olur; zaman ve hafızayı yadsır. Taktikler ise doğaları gereği geçicidir, spontane çözümler içerir. Geçmişten günümüze aktarılan popüler direniş ve isyan geleneğine dayanır. Zayıfı daha güçlü göstermede işlevseldir (Gardiner, 2016: 230-234).

De Certeau'da gündelik hayat daha çok betimlenecek bir gösteri değil, başkalarınca organize edilebilen bir eylem alanı olarak görülür. Gündelik hayatın eylem alanında ise değiş(mey)en kısımlarıyla pratikler, kullanımla şekillenen, yaşanan ve bir devamlılık çerçevesinde kamusal ve özel uzamlar ve üreticiliğin bir parçası olarak tüketim vardır (Ergin, 2018: 366).

Ayrıca Dorothy E. Smith gündelik hayatın karakteri ve cinsiyetçi sosyal tecrübe ve uygulamalarla bağlantısına odaklanarak, feminist eleştirel bir bakış açıs1 geliştirir. O, gündelik hayat dünyasında bulunma eğilimindeki marjinal gruplara devamlı uygulanan sembolik şiddetin parçası olan uzman bilgilerin içsel bağlantısını gözler önüne sermeye çalışır (Gardiner, 2016: 245-270).

Smith, ana akım sosyolojinin kavramsal ve teorik açıdan metodolojik gelişiminin gündelik hayatı ve kadınları görünmez kılma biçimlerini sorunsallaştıran bir yaklaşım geliştirir. Ona göre farklı/marjinal grupların deneyimlerini görünür kılmak, baskı mekanizmalarını açığa çıkarabilir, ama onların iç işleyiş mantığı hakkında fazla bir şey sunmaz. Farklılıkların varlığını bilmek yeterli değildir, onların ilişkili biçimde nasıl inşa edildiklerini anlamak güç olabilir. $\mathrm{Bu}$ nedenle söylem vasıtasıyla özneleri konumlandıran ve deneyimlerini üreten tarihsel süreçlerin analizi elzemdir. Smith'in bakış açısı, Marx'1 yeniden keşfedebilme adına gündelik hayat ve kadın deneyimlerini bir arada ele alarak, yönetme ilişkileri ile gündelik hayat arasındaki bağlantıyı sorunsallaştırmaya dayanır (Öztan, 2013: 38-39).

\section{Toplum, Kültür ve Gündelik Hayat}

Simmel (1950:413)'e göre, toplumsal yaşamın en sıradan dışsallıkları bile sosyo-kültürel düzenin birer yansımalarıdır. Diğer bir ifadeyle toplumsal yaşam, sosyo-kültürel düzenin temel isterleri ve dolayısıyla gündelik hayat tarafindan kuşatılmış durumdadır. Lefebvre (2007: 40), gündelik hayat içinde yaşanılan toplumun gündelikliğini ortaya çıaran niteliklerin olduğunu vurgular. Gündeliklik, toplumu anlamak için bir ipucudur. Gündelik olan kültürün veya kültürün çözülmesinin, küreselliğin, devletin merkezinde yer alır.

Tüm insanlar gündelik bir hayata sahiptir. Yeryüzünde gündelik deneyimlerin sıradan akışı herkesçe paylaşılır. Ancak örneğin beyaz orta sınıf bir erkeğin gündelik hayat pratikleri, siyahî işçi sınıfi bir kadından görece ayrıcalıklı ve farklıdır. Her ikisi de uyanma, güne hazırlanma, yemek yeme, gün içinde bir şeyler yapma vb. aynı temel rutin deneyimleri paylaşsa da bu 
deneyimlerin kadın versiyonu erkeğinkinden çok farklı olabilir. Kadının işe gitmek için sabah erken uyanması gerekebilir, yaptığı iş bedenen ve ruhen yıpratıcı, mali açıdan tatmin edici olmayabilir ve işe zamanında gitmediğinde işten atılma da dâhil her türlü yaptırımla karşılaşabilir (İnglis, 2005: 2).

Burada dikkat çekici nokta şurasıdır; farklı insanların farklı gündelik hayat deneyimleri vardır. İnsanların katıldıkları gündelik rutinler ve etkinlikler onların konumlarıyla doğrudan ilişkilidir. Belirli insanlar için gündelik hayatın nasıl yapılandırıldığını anlamak adına, onların hayatlarını idame ettirdikleri toplumun nasıl yapılandığını ve organize edildiğini iyi analiz etmek gerekir. Basit bir biçimde gündelik hayatı açıklamak için onu ilgi çekmeyen ve sıkıcı etkinliklerin bir bütünü olarak görmenin ötesinde daha geniş toplum ve sosyal yapıların gündelik hayatı, farklı türden insanlar için nasıl ürettiğini anlamak gerekir. Bu anlamda sosyoloji, gündelik hayatın daha derin manalarını, farklı biçimlerde cereyan eden gündelik hayat deneyimlerinin oluştuğu sosyal bağlamları ve toplumsal yapı ve organizasyonun gizli yönlerini deşifre etmeye çalışır (İnglis, 2005: 3).

Gündelik hayatın açıklanmasında sosyal yap1 ve örgütler ne kadar önemliyse toplum ve toplumun belirli yönlerinin nasıl işlediğinin anlaşılması bakımından da gündelik hayat pratikleri ve deneyimlerinin analizi o kadar mühimdir. Toplum ve gündelik hayat arasındaki ilişkiyi bu çerçevede sınırlandırmak doğru değildir. Sosyal yapı ve kurumlar aynı zamanda kültürün temel unsurları arasında yer alır. $\mathrm{Bu}$ bağlamda kültür ve gündelik hayat arasındaki ilişki de kendiliğinden ortaya çıkar. Çünkü hiçbir toplum yoktur ki üyeleri belirli değerler sistemine, dayanışma ağlarına, inançlara, sosyal normlara ve fikir kalıplarına sahip olmasın. Toplum ancak bunlarla var olur. Yani her toplum için kültürel formlar önemli bir kaynaktır. Bu anlamda da insanın kültürel bir varlık olduğu gerçeği ortaya çıkar.

Kültür, çoğunlukla sembollerle edinilen ve aktarılan düşünme, hissetme ve tepki verme kalıplarından oluşur. Kültürün odağında geleneksel anlayışlar ve ilişkili değerler vardır (Kluckhohn, 1951: 86; Hofstede, 2001: 9). Sübjektif terimlerle tanımlanabilen kültür, bir toplumdaki normların ve pratiklerin temelini oluşturan, neyin doğru neyin yanlış ya da neyin meşru neyin gayri meşru olduğuna dair anlamlar, semboller ve varsayımlar kompleksini ifade eder ve genellikle bir dizi ortak değer ve inanç bağlamında tanımlanır (Licht ve Siegel, 2006: 516-517). Hofstede ve arkadaşları (2010: 6) kültürü, öğrenildiği ortam ve aynı sosyal çevrede yaşayan insanların belirli seviyelerde paylaştığı kolektif bir olgu olarak değerlendirir. $\mathrm{Bu}$ olgu, sosyal yaşamın yazısız kurallarını içerir ve bir grubun veya insan "kategorisi"nin üyelerini, diğerlerinden ayıran zihnin kolektif bir programlamasıdır.

Kültür, sosyal yaşamdaki temel değerleri ve zihniyet yapısını içerisinde barındırır ve belirli tutum ve davranışların oluşturulması ve geliştirilmesinde işlevseldir. Bu açıdan kültür, birey ve toplum üzerinde temel bir etkisi söz

konusudur. Kültür, belirli davranış kalıplarının üretilmesi ve kitleselleştirilmesinde önemli bir role sahiptir (Aytaç ve Y1lmaz, 2020: 210). Kültür insani olana ilişkin yapıp etmelerin bir genellemesidir. Bir açıdan kültür insana ait olan her şey ister yerküre ister boşluk olsun, mekân üzerinde bıraktığımız ve tarihsel bakımdan silinmesi güç bütün izlerin birikimini karşılar. Diğer bir deyişle kültür, zaman ve mekân tutunumlu bir eylemeler dünyasıdır. Yani zamansal olduğu kadar mekânsal boyutu da vardır kültürün. Bu bakımdan 
gündelik hayatta çoğu şeyi ele verir bir yapı söz konusudur. Gündelik hayat akıp giderken duruma vaziyet etmek, dağınık, birbiriyle bağlantısız görünen kültür, iktisat, siyaset gibi hayat fragmanlarının tarih ana kıtasındaki bağlarına işaret eder (Öğün, 2006: 1-5).

İnsanoğlunun yaşam alanlarını, alışkanlıklarını, birlikte yaşama süreçlerini ve daha da önemlisi zihniyet alışkanlıklarının temel anlamını içermesi bakımından toplumsal-kültürel yapılar, (Bourdieu'nun kavramsallaştırmasıyla habitus un) gündelik hayat temelinde kodlanır. Kısacası, gündelik hayat sosyo-kültürel bir habitusu imler. Toplum üyeleri tarafindan içselleştirilen, bedenselleştirilen toplumsal yapılar olarak habitus, gündelik hayat pratiklerine sirayet ederek bu alanların kurulumuna zemin oluşturur ve imkân sağlar.

Örneğin Afrika'da Bostwana ve Namibya'daki Kalahari çölünde yaşayan Busmen diye de bilinen! Kung'ların, dış etkilerden yaşam tarzları değişse de geleneksel toplum kalıpları dikkat çeker. Su kuyularının yakınındaki yerleşimlerde, 30-40 kiş̧ilik gruplar halinde yaşarlar. Yiyeceğin kıt olduğu bir coğrafyada yaşadıklarından yiyecek temini için uzun yürüyüşler yaparlar. Yani günler çoğunlukla yürüyerek geçer. Topluluk üyeleri kimi zaman 100 millik bir alanı bir günde taramak zorunda kalır. Suyun ve yiyeceğin bol olduğu yağmur mevsiminde ise gündelik rutinler ve etkinlikler değişir. Bu süreçte! Kung'ların gündelik hayatları, tören ve ayin etkinlikleri etrafında yoğunlaşır, bunlara hazırlık ve gerçekleştirme çok zaman alıcıdır. Bu grupların çoğu hiçbir zaman iyi tanımadıkları hiç kimseyi görmez. Yani "yabancı" algıları ve buna ilişkin sözcükleri yoktur. Topluluk içinde pek az mahremiyet firsatı vardır. Aileler derme çatma tüm etkinliklerin dişarıdan göründüğü açık evlerde yaşar. Kung'ların etkinlikler ve etkileşimler bakımından modern toplumlarda yaygın olan odaların duvarları, ayrı binalar ve kentlerin değişik mahalleleri tarafindan dışarıya kapanmasından farklılaşır. Kent yaşamı üyelerini sürekli yabancılarla etkileşim kurmaya zorlar (Giddens, 2008: 188-190).

Gündelik hayat, insanın günlük etkinliklerini yapılandıran sosyal konumu bilmekle açıklanamaz aynı zamanda içinde faaliyet gösterdiği kültürel koşulların da bilinmesi gerekir. Özellikle kompleks yapıdaki modern toplumlarda her insanın içinde işlediği kültürel şartlar çokludur ve birbiriyle örtüşür. Örneğin Batı kültürlerinde yaygın fikirler, kavramlar, eğilimler, düşünme ve hissetme biçimlerine bakıldığında bireyciliğe ve özerkliğe yapılan vurgu önemli kültürel karakteristiklerin göstergesidir. Bununla birlikte, belirli ülkelerin, şehirlerin ve kasabaların, topluluk ve komşuluk ilişkilerinin, yer ve mekânların "kültürleri”" kişinin gündelik faaliyetler ve deneyimler yaratmasında yardımcıdır. Örneğin Batı toplumlarında bireye ve özerkliğine vurgu bakımından fikirsel, kavramsal, düşünme ve hissetme biçimleri gibi kültürel kodların önemi yadsınamaz, çünkü her sosyal kolektivitenin bir dizi kültürel özellik barındırdığı aşikârdır (İnglis, 2005: 4).

Benzer biçimde Hofstede (2001: 29), kültürün birer yansıması olarak ulusal kültürlerin, kurumlar/örgütler, davranışlar ve değerler açısından birbirinden farklılaştığını vurgular. Ona göre, kültürün güç mesafesi, belirsizlikten kaçınma, baskın(eril/dişil) değerler, bireycilik-toplumculuk ve kısa vadeye karşı uzun vadeye yönelim gibi temel boyutları açısından ulusal düzeyde kültürel farkl11ıklar gözlemlenir. Örneğin Hofstede (2001:227), ulusal kültürlerin, bireyci-kolektivist kültürel değerlere göre farklılaşması üzerinde 
durur. $\mathrm{Bu}$ farklılaşma girişimci kültürü de etkiler. Bireyciliğin düşük olduğu kolektivist kültürlerde bireyler korumacı bir yapı (aile, klan vb.) içinde doğar, "biz" bilinciyle ve topluluk (gemeinschaft) düşüncesiyle hareket eder, topluluğa yönelim ve bağl1lık önemsenir, değer standartları grup içinde ve dişında farklılaşır, kimlik sosyal sistem kaynaklı edinilir ve geleneksel değerler baskındır. Bireyciliğin yüksek olduğu kültürler de ise toplumdaki herkes sadece kendi ailesinden sorumludur, "ben" mantığı ve toplum (gesellschaft) düşüncesi hâkimdir, öze-kendine yönelim söz konusudur, değer standartları herkese evrensel olarak uygulanır ve özel yaşamın önemi vurgulanır. Bu tür kültürel değerler gündelik hayat pratiklerini de benzer tarzda kodlar. Bu açıdan günlük yaşamın idamesinde girişimci etkinliklerin, edimlerin ve kültürel kodların ortaya çıkması, desteklenmesi ve geliştirilmesi söz konusudur.

Bunun yanında toplumsal farklılaşmanın temellerini gündelik hayat pratiklerinde aramak da yerinde bir adımdır. Chaney (2002: 5)'e göre, gündelik hayatın nasıl değiştiği modern çağa özgü gelişmeler bağlamında açılanabilir. $\mathrm{Bu}$ ifadeden gündelik hayatın sadece modern dönemde ortaya çıktığ 1 anlamı çıkarılmamalıdır. Daha çok gündelik hayat kategorisinin bir sosyal teori konusu ve kültürel temsil teması haline gelmesinin modern zamanlarla birlikte oluştuğu anlatılmaya çalışılır.

$\mathrm{Bu}$ bakımdan modern batı kültürleri gündelik hayatın rasyonelliği temelinde analiz edilir. Weber'in Batı toplumlarındaki yüksek rasyonalite düzeylerine ilişkin araştırmaları, bu konuda öncü çalışmalardandır. Weber, insanların resmi prosedürlere dayanan akılcı bir kültür içinde etkinlikte bulunma temelinde nasıl düşündükleri ve hareket ettikleriyle ilgilenir. Onun için modern kültür, belirli hedeflere erişimi verimli derecede sağlayabilecek rasyonelleştirilmiş kurallar ve prosedürler dolayımında çözümlenebilir. Modern kültürle birlikte Batı toplumlarında gelenek ve dinin kontrol gücü zayıflar ve bunun yerini yeni bir otorite tipi doldurur. Weber bunu yasal-ussal otorite olarak kavramsallaştırır. Modern bireylerin düşünce yapısı ve tüm etkinlikleri belirli normların sistematik biçimde uygulanmasıyla organize edilir ve sınırlandırılır. Bu, ideal bürokrasi kuramı bağlamında formülleştirilir (İnglis, 2005: 29).

Örneğin modern toplumlarda çalışma kültürüne ilişkin birçok değer kökten dönüşüme uğrar. Ev ekonomisine dayalı küçük çaplı zanaatkâr üretimin yerine fabrika merkezli kitlesel üretim anlayış1 geçer. Geleneksel toplumun bağımlı çalışma kültürü, bireysel ve başarı odaklı bir çalışma kültürüne dönüşür. $\mathrm{Bu}$ dönüşüm iş hayatı odaklı ve sosyo-kültürel alandaki gündelik hayat pratiklerinin de yeniden üretilmesine neden olur. Bürokratik kurallara göre, hangi işin kim tarafından hangi saatler arasında, hangi yoğunlukta yapılacağı önceden belirlenmiş bir sistem oluşturulur. Bu duruma uyum sağlayacak yeni bir iş̧̧i tipi yaratılır. Uygulamanın sahadaki temsilcisi H. Ford'tur. Kendi araba fabrikasında örgütsel kültüre içerilmiş çalışanların üretilmesi temel hedeftir ve bunu gerçekleştirme adına çalışanın gerek iş gerekse iş dışı gündelik pratikleri sıkı bir denetim ilişkisiyle istenen örgütsel kişilik/işçi/insan tipinin inşa edilmesi temel hedeftir.

Lefebvre (2007: 46) modern çağda gündelik hayatın toplumsal sınıflara göre ayrıştı̆̆ını belirtir. Bu farklılaşma sadece gelir miktarına değil gelirin niteliğine yani ödeme biçimi; maaşlara, ödentilere, rantlara bağlı saat başı, haftalık, aylık, yıllık ödeme vs. gelirlerin işletilmesine ve nasıl organize 
edildiğine göre de karş1lık bulur. Mesela işçi sınıfı günü gününe yaşama, birikim sağlayamama gibi nitelikleri bakımından benzeşir.

Habermas'a göre, modern bürokratik kurumlardaki araçsal akılc1 eylemler, yerine getirdikleri görev alanlarının dışına çıkarak gündelik kültüre sirayet eder ve gündelik yaşam alanlarını dönüştürerek kurumsallık eklemli gündelik hayat fragmanları oluşturur. Habermas, modern zamanlarda gündelik hayatın akılcılaşmasını ve araçsallaşmasını bürokratik eylem sistemlerinin gücüyle açıklar. Ona göre, böylelikle yaşantı dünyası bağımlı hale gelir. Modern bireyler sistem amaçlarına içkin olarak bilinçlendirilir ve buna uygun kültürel değerler ve kimliklerle kuşatılırlar. Modern hayatın akılcı kriterleri, bürokrasi veya farklı kurumsal yapıları, tümüyle günlük yaşam alanlarının kolonizasyonuna neden olur (Aytaç, 2005: 335).

Lefebvre (2017: 94) modern bürokrasinin hiyerarşik yapısının en alttan en tepeye (iş, gelir, nesneler, mülkler, bireye ve gruplara verilen nitelikler, toplum, medya, bilgi, ideoloji ve otoriteye) kadar sirayet ettiğini belirtir. O, modern bürokrasiyi, gündelik hayatı ve gündelik hayat kapsamındaki bireyleri, kendi çalışmasının hammaddesi, işlenecek bir kitle, yardım gören bir halk olarak görmesi bakımından eleştirir.

Modern öncesi kültürel yapılar belirli bir sürecin ürünü olarak ortaya çıktıkları toplumun kimliğinin oluşmasında etkindir. Türk kültürü, Hint kültürü, Alman kültürü vb. örnekler ait oldukları toplumları tanımlamada ve onlara bir kimlik atfetmede işlevseldir. İnsanoğlu yaşadığı toplum kültürünün rengine boyanır, aynı zamanda kendi rengiyle de üyesi olduğu kültüre renk katar. Batı toplumlarında modernleşme süreciyle rasyonellik, nesneleşme anlamında yabancilaşmaya neden olur. Bu süreçte bireysel ve toplumsal ürün olarak kültür de payına düşeni fazlasıyla alır. Kültür endüstrisi kavramı, kültürün rasyonelleşme süreciyle nesneleşmesi yani meta haline gelmesini karşılar (Çetin, 2017: 42). Modern zamanlarla birlikte kültürün her şey üzerinde benzerlik türettiğini, izlenen filmlerin, dinlenen radyo programlarının ve okunan dergilerin bir sistem oluşturduğunu savunur. $\mathrm{Bu}$ süreçte kültür, meta üretimi sektöründeki üretim ilkelerine uygun işleyen bir sanayi koludur ve kültürel üretim modern kapitalist ekonominin ayrılmaz bir parçası haline gelir (Adorno, 2009: 19). Bu anlamda modern toplumlarda kurumsal yapıların yanında kültürel alan ve gündelik hayat daha çok homojenleştirici nitelikleri bağlamında bütünleştirici/tek tipleştirici bir fonksiyon yerine getirir.

De Certeau, modernliğin bu yönüne eleştirel bir bakış geliştirir. Ona göre, gündelik hayatın rastgele bir alanında sıradan bireyin çeşitli kullanım biçimleri oluşturarak ortaya çıkardığı yaratıcı alternatifler ve taktikler, temelde tek tipleștirme ve üst yapısal düzenlemeciliğin hâkimiyetine karşı bir konumlanır. Temelde bu yaklaşım, kültürel çalışmalar bağlamında alternatif bir duruştur. Çünkü gündelik hayatın sıradan ama görünmeyen kısımlarında homojenleştiriciliğe, tektipleştiriciliğe karşı duruş olarak çoğulcu kültürler yaratilır (Y1lmaz, 2017: 3).

20. yy. sonları ve 21. yy. başlarından itibaren toplum ve kültürel alan ile ilişkisi bağlamında gündelik hayat, modern zamanlara nazaran çok daha dinamik, son derece çoğul ve çekişmeli bir alan olarak değerlendirilir. Artık sınıfsal, mesleki ve cinsiyet temelli modern kimlik algılarının önemini kaybetmesi ve kültür-medya endüstrilerinin yıldızlarının parlaması modern gündelik hayat pratiklerinin de dönüşümüne zemin hazırlar. Artık kültür, çeşitli 
kimlik projelerini içeren, fragmanlara ayrılmış ve çoğulcu bir yapıya kavuşur. (Bennett, 2013: 14).

Kültürün yerel ve kadim niteliklerinin etkisi zayıflar. Yerel küresel arasındaki yöndeşme gündelik hayat deneyimlerine de yansır. Gündelik hayat kültürel açıdan kurulan çekişmeli bir alan haline dönüşür. Gündelik hayatın "kültürel parçalanma"sı küresel mobilitenin yükselişiyle etkiselliğini artırır. Eskiden göreli olarak durağan ve etnik açıdan benzeşen topluluklarla belirgin sınırlara ayrılmış gündelik hayat, günümüzde uzamsal ve mekânsal anlamda plüralist ve çetin yapıya dönüşerek, akışkan ve kültürel melezleşme prosesleriyle sürekli yeniden tanımlanır hale gelir (Bennett, 2013: 16). Modern dönemlerden günümüze gelindikçe gerek kültürün gerekse gündelik hayatın daha karmaşık ve fragmanlara ayrılmış bir hale geldiği ve her iki alanında tekilleştirilmiş ve homojen yapısının yerini giderek heterojen ve farklılaşan bir yapının aldığı söylenebilir.

Küreselleşme süreci aynı anda iki kültür imgesini akla getirir. İlk imge belirli bir kültürün kendi sınırlarının dışına doğru genişlemesidir. Heterojen kültürler, tüm dünyayı kapsayan baskın bir kültürle birleşir ve bütünleşir. İkinci imge ise kültürlerin sıkışmasıdır. Bir arada düşünülemeyen şeyler artık temas halinde ve yan yanadır. Kültürler yığınlar halinde üst üste biriktirilir. Pratik bilgi, yönlendirme araçları ve tutarlı inanç sistemleri kapsamında ele alınan ve organize edilen çoğulcu bir kültür yapısı vardır (Featherstone, 2000: 6).

Küresel koşullar altında yerelin veya bizim yerel olarak düşündüğümüz şeyin, artık belirli bir yere özgü kültürel belirleyiciliği ortadan kalkar ve kültürel olgular binlerce mil uzaktaki yerlere nakledilebilir ve oralarda kök salar. Yaygın kültürel transplantasyonlar küreselleșen dünyanın en temel niteliğidir. Küresel çağda, hem Amerikan kültürü öncülüğündeki küresel bir kültür iktidarıyla yaratılan dünya çapında tekdüzelik ve aynılık ile hem de kültürel melezlik, farklılık ve yerelliğin-özgüllüğün yeniden doğrulanmasıyla karakterize edilen çeşitli kültürel dinamikler vasıtasıyla gündeliklik yeniden üretilir (İnglis, 2005: 81-94).

Küreselleşme ile melez pratikler din, müzik, spor, dil, festival gibi birçok kültürel alanda kendini gösterir. Örneğin Gandi "Hindu, İslami, Budist ve Hıristiyan öğeler ile düşüncelerini kendine özgü bir tarzda birleştirerek kendi dinini" oluşturan biri olarak değerlendirilebilir ve kolektif seviyede ele alındığında görece yeni olan bu dinler, açık bir biçimde melezleşme örneği (Burke, 2011: 42) olarak gündelik pratiklerin de benzer tarzda deneyimlenmesini sağlar.

Küresel çağda post modern kültürel süreçlerle birlikte kurumlar, endüstriler vb. birçok alanda kültürel faaliyetleri sınırları belirli ayrı bir kültür alanı olarak ele almak zorlaşıyor. Burada genel sosyal faaliyetler yelpazesi içinde kültür yayılımı, fragmanlara ayrılmış bir süreç olarak karakterize edilir (Chaney, 2002: 170). Post modern kültürde gündelik hayat, bir sömürü ve bask1 alanı olmaktan çıkar. Kültürel değerlerin çoğulluğunun, insanın düşünümsel olarak kendisini, öteki ile olan ilişkilerini ve nesnelerin fiziki ve sembolik anlamlarını deşifre eden, çekişen duyarlılıklara kapı aralanan bir alandır (Bennett, 2013: 92). Bu anlayış, gündelik olanın sorun alanı olarak görülmesi ve çözüm yerinin de gündelik hayat olarak belirlenmesi açısından önemlidir.

Artık kültürel anlamın ve eylemin odağında birey yer alır. Birey gündelik hayatta kültürel üretimin merkezinde bulunarak pasif tüketiciler yerine 
ilişkide bulundukları/tükettikleri nesneleri, imgeleri yeniden üretirler. Post modern gündelik hayat farklı kültürel alanların açıklığa kavuşturulmasında işlevseldir. Medya ve yeni medya araçları, moda, müzik, spor vb. birçok alanda bu etkiyi görmek mümkündür. Örneğin Kellner (1995: 17; Bennett, 2013:123) medya kültürü konusundaki incelemesinde, medyanın/yeni medyanın kendine has imge ve zevkleri, zihniyetin ve değerlerin temel belirleyicisi olarak aile, okul ve dini yapıların yerini ünlülerin almasıyla yeni ve çeşitli kimliklerle uyumlu yaşam tarzları, buna uygun giyim ve davranış formlarına içerilmiş imgelerin baskın hale geldiği bir sosyalleşme gücü üretir.

Post modern kültüre içkin gündelik hayatını idame ettirmeye çalışan birey zamana özgü bir insan tipi olarak üretilir. Post modern birey aşkın normlardan ve insani değerlerden geleneksel bağlarından özgür olmayı amaçlar. Bu dönemin insanı rahat ve esnektir. Duygu ve hisler baskındır. Aktif bir yapıda kişisel bir yol takip eder. Gerçeklik iddiasında değildir. Sürekli olan yerine geçici olan seçilir. Egzotik, kutsal ve nadir olana yönelir. Birçok referanstan hareketle gündelik yaşamını sürdürür (Bozkurt, 2012: 75).

\section{Sonuç}

Gündelik hayat, toplumsal yapı ve kültürel değerlerle karşı1lıklı bir ilişki içerisindedir. Zamana ve mekâna göre toplumların kendilerine has kültürel kodları ve bunun gündelik hayata yansımaları vardır. Bireysel ve toplumsal yaşama ilişkin önemli ipuçları sunan gündelik hayata, sosyo kültürel bir bakış açısıyla yaklaşmak işlevsel kabul edilebilir.

Gündelik hayat herkes için vardır. İnsanoğlunun kişisel ve sosyal eylemleri, tutum ve etkinlikleri, toplumsal etkileşim ve ilişkileri gündelik hayat tarafından çepeçevre sarılıdır. Sosyal normlar ve kültürel kodlar gündelik hayat temelli ve kişinin benliği ve sosyal benliği ile uyumlu bir biçimde gelişim gösterir. Bazen de aykırı etkinlikte bulunabilir. Ancak her iki durumda da ortak payda gündelik hayattır. Örneğin girişimci kültür bireysel ve toplumsal düzeyde farklılaşan gündelik hayat pratiklerine ve deneyimlerine atıfta bulunur. Gerek sosyal yapı, aile, ekonomik faaliyetlere katılım, eğitim vb. faktörler açısından değişen gündelik hayat kültürleri ortaya çıkar. Birey ekonomik etkinliğe içkin bir benlik gelişimiyle gündelik hayatını sürdürür ve toplumsal etkileşimlerinin temelinde de bu tür günlük yaşantıların varlığı söz konusudur.

Modern öncesinden modern zamanlara ve modern sonrası dönemlere gelinceye dek gündelik hayat pratiklerinin toplumsal, kültürel iktisadi vb. yapılarla bağlantılı biçimde gelişim gösterdiği görülür. Modern öncesi toplumlarda geleneğin/dinin baskın değerleri gündelik hayatın her anını kuşatarak buna uyumlu ilişkisellikler üretir. Modern toplumsal yapıda rasyonel, rutin, monoton vb. gündelik kültürlerin/etkinliklerin yayılımı söz konusudur. Post modern zamanlarda kültür, kimlik yapılarının çoğullaşması, parçalı bir görünüm sergilemesi gündelik hayatın tüketilme biçimlerinde de benzer niteliklerin ortaya çıkmasına yol açar. Günümüzde parçalanmışıl̆ğı, çoklu yapıların çeşitlilik göstermesi bireyselleşmeyi, yabancılaşmayı daha da derinleştirir. Böylelikle bireysel ve toplumsal alanda gündelik hayat etkinlikleri de bütünlükten yoksun fragmanlara/kompartımanlara ayrılmış ve iç içe geçmiş bir gelişim arz eder. Özellikle dijitalleşmenin getirdiği sosyal norm ve kültürel değerler, eskiye ait tüm alışkanlıkları, rutinleri, tutumları dönüştürerek günlük yaşantıların da paralel tarzda değerlendirilmesinin önünü açar. 
Çıkar Çatışması Beyanı / Conflicts of Interest Statement:

Çalışmada çıkar çatışması bulunmamaktadır.

There is no conflict of interest in the study.

\section{Maddi Destek / Financial Support:}

$\mathrm{Bu}$ çalışmada herhangi bir fon veya maddi destekten yararlanılmamıştır.

No funding or financial support was used in this study.

Yazar Katkıları / Contribution Rate of the Authors:

Fikir: MY; Tasarım: MY; Veri Toplama: MY; Kaynak Tarama: MY; Analiz ve Yorum: MY; Makalenin Yazımı: MY.

Idea: MY; Design: MY; Data Collecting: MY; Literature Review: MY; Analysis and Discussion: MY; Writing: MY.

(!) Yazar/yazarlar bu çalışmanın tüm süreçlerinin araştırma ve yayın etiğine uygun olduğunu, etik kurallara ve bilimsel atıf gösterme ilkelerine uyduğunu beyan etmiştir. Aksi bir durumda Medeniyet Araştırmaları Dergisi sorumlu değildir.

(!) The author/authors declared that all processes of this study are in accordance with research and publication ethics, and comply with ethical rules and principles of scientific citation. Otherwise, the Journal of Civilization Studies is not responsible.

\section{Kaynakça}

Adler, P. A. - Adler, P. - Fontana, A. (1987). Sociology of Everday Life. Annual Review of Sociology. (13), 217-235. Çev. Bekir Balkız (2012). Gündelik Hayat Sosyolojisi. Sosyoloji Dergisi (27) 115-139.

Adorno, T. W. (2009), Kültür Endüstrisi, (Çev. N. Ülner-M.Tüzel-E.Gen), İstanbul: İletişim Yay.

Arygle, M. (1972) The Psychology of İnterpersonal Behaviour, Second Ed. PenguinBooks.

Arygle, M. (1994). The Psychology of İnterpersonal Behaviour, Fifth Ed. Penguin Books.

Aytaç, Ö. (2005). Modern Bürokrasiler ve Yabancılaşma Ethosu. Fırat Üniversitesi Sosyal Bilimler Dergisi, 15(2), 319-348.

Aytaç, Ö. ve Yılmaz, M. (2020), Kültür ve Girişimcilik. Ed. M.Y.Alptekin içinde, İktisat Sosyolojisi, Ankara: Nobel Yay. (207-231).

Bauman, Z. (2011). Postmodern Etik, (Çev.A. Türker), İstanbul: Ayrıntı Yay. (2.Basim).

Bennett, A. (2013). Kültür ve Gündelik Hayat. (Çev. N. Tokdoğan, B.Şenel, U. Y. Kara), Ankara: Phoneix Yay.

Berger, P. ve Luckmann, T. (2008). Gerçekliğin Sosyal İnşası, Bir Bilgi Sosyolojisi İncelemesi. (Çev. V.S. Öğütle), İstanbul: Paradigma Yay.

Binay, B. ve Tatlıcan, Ü. (2018). Sembolik Etkileşimcilik ve Gündelik Hayatın Sosyolojisi Ed. A. Esgin ve G. Çeğin içinde, Gündelik Hayat Sosyolojisi, Ankara: Phoneix Yay. (147-190).

Binici, U. ve Tatlican, Ü. (2018). Harold Garfinkel'in Etnometodolojisinde Gündelik Hayat. Ed. A. Esgin ve G. Çeğin içinde, Gündelik Hayat Sosyolojisi, Ankara: Phoneix Yay. (213-234).

Bozkurt, V. (2012). Endüstriyel ve Post-Endüstriyel Dönüşüm. Bursa: Ekin Yay. 
Burke, P. (2011). Kültürel Melezlik. (Çev. Mustafa Topal). İstanbul: Asur Yay.

Certeau, M.de (2002). The Practice Of Everyday Life. (Trans. S. Randall), London: University of California Press.

Chaney, D. (2002). Cultural Change and Everyday Life, Basingstoke, Hampshire: Palgrave.

Çetin, E. (2017). Gündelik Hayata Sosyolojik Bakmak, Ankara: Siyasal Yay.

Debord, G. (1961) Perspectives for Conscious Alterations in Everyday Life. in Ken Knabb (ed.), The Situationist International Anthology, Bureau of Public Secrets, Berkeley.

Durkheim, E. (1982). The Rules of Sociological Method. New York: Free Press.

Elias, N. (1994). The Civilizing Process. Oxford: Blackwell.

Ergin, N.B. (2018). Siradan İnsanların Gündelik Sanatları: De Certeau ve Gündelik Hayat. Ed. A. Esgin ve G. Çeğin içinde, Gündelik Hayat Sosyolojisi, Ankara: Phoneix Yay. (343-370).

Esgin, A. (2018). Gündelik Hayat Sosyolojisi: Tarihsel Süreç ve Temel İlkeler. Ed. A. Esgin ve G. Çeğin içinde, Gündelik Hayat Sosyolojisi, Ankara: Phoneix Yay. (13-34).

Esgin, A. ve Özben, M.(2018). Klasik Sosyoloji ve Gündelik Hayat: Durkheim'dan Parsons'a. Ed. A. Essgin ve G. Çeğin içinde, Gündelik Hayat Sosyolojisi, Ankara: Phoneix Yay. (35-52).

Featherstone, M. (2000). Undoing Culture Globalization, Postmodernism and Identity. SAGE Pub.

Felski, R. (2000). Doing Time: Feminist Theory and Postmodern Culture. New York and London: NYU Press,

Freud, S. (1975). The Psychopathology of Everyday Life. Harmondsworth: Penguin.

Freud, S. (1996). Günlük Yaşamın Psikopatolojisi, (Çev.Ş. Yeğin) İstanbul: Payel Yay.

Gardiner, M. (2016). Gündelik Hayat Eleştirileri.(Çev. D. Özçetin vd.), Ankara: Heretik Yay.

Giddens, A. (2008). Sosyoloji, (Yay. Haz. Cemal Güzel) Kırmızı Yay. İstanbul.

Goffman, E. (2009). Günlük Yaşamda Benliğin Sunumu. (Çev. B. Cezar). İstanbul: Metis Yay.

Güven, U.Z. (2018). Kültür, Gündelik Hayat ve Teatrallik İlişkisi Açısından Performans Antropolojisi. Antropoloji, (36), 103-123.

Heller, A. (1987). Can Everyday Life Be Endangered?. Philosophy and Social Criticism, 13 (2), 297-313.

Highmore, B. (2002). Everyday Life and Cultural Theory, An İntroduction, Routledge Pub.

Hofstede, G. (2001). Culture's Cosequences: Comparing Values, Behaviours. Institutions and Organizations Across Nations, Sage Pub. Second Edition.

Hofstede, G.- Hofstede, G. J. ve Minkov, M. (2010). Cultures and Organizations: Software of the Mind Intercultural Cooperation and Its Importance for Survival, McGraw-Hill.

İnglis, D. (2005). Culture and Everyday Life. London and New York: Routledge, Taylor\&Francis Group. 
Kluckhohn, C. (1951). The study of culture. in Lerner, D. \&Lasswell, H.D. (Eds.), The policy sciences. Stanford, CA: Stanford University Press.

Köse, H. (2018). Yaban Bilinç ya da Lefebvre'e Göre Gündelik Hayat. Ed. A. Esgin ve G. Çeğin, Gündelik Hayat Sosyolojisi. Ankara: Phoneix Yay. (305-341).

Layder, D. (2006). Sosyal Teoriye Giriş. (Çev. Ü.Tatlıcan) İstanbul: Küre Yay.

Lefebvre, H. (2007). Modern Dünyada Gündelik Hayat. (Çev. Işın Gürbüz). İstanbul: Metis Yay.

Lefebvre, H. (2015). Gündelik Hayat Eleştirileri II Gündelik Hayat Sosyolojisinin Temelleri. (Çev. I. Ergüden). İstanbul: Sel Yay.

Lefebvre, H. (2017). Gündelik Hayat Eleştirileri III, Moderniteden Modernizme (Gündelik Hayatın Meta-Felsefesi). (Çev. I. Ergüden), İstanbul: Sel Yay.

Licht, A. N. ve Siegel, J. I. (2006). The Social Dimensions of Entrepreneurship. edit. by Mark Casson vd. içinde Oxford Handbook of Entrepreneurship, New York: Oxford University Press. (511-540).

Marshall, G. (2009). Sosyoloji Sözlüğü. (Çev.O. Akınhay ve D. Kömürcü) Ankara: Bilim Sanat Yay.

Orhan, C. (2018). Avamperestane Vehmedilenin Kurnazlı̆̆ı: Erving Goffman. Ed. A.Esgin ve G. Çeğin içinde, Gündelik Hayat Sosyolojisi, Ankara: Phoneix Yay.(191-212).

Öğün, S.S. (2006). Günlük Hayatın Kültürel Yansımaları, İstanbul: Alfa Aktüel Yay.

Öztan, E. (2013). Dorothy Smith'in Sosyal Bilim Yaklaşımı ve Kurumsal Etnografya. Sosyoloji Konferansları No: 48 (2013-2) / 35-56.

Parsons, T. (1951). The Social System. London: Routledge \& Kegan Paul.

Polama, M. (1993). Çağdaş Sosyoloji Kuramları,(Çev. H. Erbaş), İstanbul: Gündoğan Yay.

Sayar, K. ve Dinç, M. (2013). Psikolojiye Giriş İstanbul: Dem Yay.

Scott, S. (2009). Making Sense of Everyday Life. UK and USA: Polity Press.

Sheringam, M. (2006). Everyday Life, Theories and Practices from Surrealism to the Present, New York: Oxford University Press.

Simmel, G. (1950). Metropolis and Mental Life. K. H.Wolff (trans. and ed.) içinde, The Sociology of Georg Simmel, New York: Free Press.

Slattery, M. (2008). Sosyolojide Temel Fikirler (Yay. Haz. Ü.Tatlican-G. Demiriz) Bursa: Sentez Yay.

Swingewood, A. (1998). Sosyolojik Düşüncenin Kısa Tarihi (Çev. O.Akınhay), Ankara: Bilim ve Sanat Yay.

Şentürk, Ü. (2018). Husserl ve Schutz: Fenomenolojik Perspektif. Ed. A. Esgin ve G. Çeğin içinde, Gündelik Hayat Sosyolojisi, Ankara: Phoneix Yay. (235-268).

Wallace, R.A. ve Wolf, A. (2012). Çağdaş Sosyoloji Kuramları, Klasik Geleneğin Genişletilmesi. (Çev. M.R.Ayas ve L. Elburuz). Ankara: Doğu Batı Yay.

Yılmaz, G. G. (2017). Gündelik Hayat Sosyolojisinden Kente ve Kültüre Bakmak; Certeau'cu Bir Taktik Alanı Olarak Kent”, 1-12. https://www.academia.edu/33390034 (Er.24.01.2021). 